\title{
Access to care for workers' compensation patients in dense and sparse population centers
}

\begin{abstract}
Background: Workers' compensation was originated to provide a no-fault, timely access to appropriate medical care. Unfortunately, we have found that the system fails the injured worker in certain environments. By implementing procedural roadblocks in the form of initial claim denial and delay methods, the injured worker finds himself/herself in a battle of attrition. By delaying treatment and compensation benefits, the injured workers are "starved out" of their access to care and often walk away from their claim or accept a payout without treatment.

Methods: We performed a randomized, consecutive case-series where 300 hypothetical patients called medical offices to attempt to arrange a physician consultation. We analyzed the ability of a patient to gain access (an appointment) to a primary care $(\mathrm{N}=100)$, orthopedic $(\mathrm{N}=100)$ and neurology $(\mathrm{N}=100)$ physician after stating that they were injured at work. We analyzed two cohorts, one as an injured worker that was given a claim number $(\mathrm{N}=150)$ and the other that was injured at work but not yet given a claim number $(\mathrm{N}=150)$.

Conclusion: This study demonstrates how difficult it is to gain access to care as an injured worker. An injured worker in a low densely populated area without a claim number was unable to gain access to a primary care doctor in our cohort (100\% denial rate). Even a patient with an accepted claim number in densely populated Cook County, IL had a $52 \%$ chance of being denied access to care with an orthopedic surgeon while a patient without a claim number had an $84 \%$ chance of being denied access to orthopedic care.
\end{abstract}

Keywords: workers compensation, access to care, orthopedic, neurology, primary care, denial to care
Volume 12 Issue 3 - 2020

\author{
Blair A Rhode,' Skylar M Rhode 2 \\ 'Orthopedic Surgeon, Orland Park Orthopedics, USA \\ 2Research Associate, Rhode Orthopedic Research Institute \\ (RORI), USA
}

Correspondence: Blair A Rhode, Orland Park Orthopedics, 16450 S 104th AV, Orland Park, Illinois 60467, USA, Tel 708-364-844I, Fax 708-364-8443, Email Blairbones@gmail.com

Received: May 03, 2020 | Published: May 15, 2020

\section{Introduction}

Workers' Compensation is a state mandated no-fault system form of insurance that ensured that workers injured at work would receive compensation without delay and without regard to fault (820 ILCS 305/1(a) (3)). ${ }^{1}$ It traces its origins back to Germany, where Chancellor Otto Von Bismarck introduced a compulsory state-run accident compensation system in 1884. It is a benefit provided in exchange for mandatory relinquishment of the employee's right to sue his or her employer under the common civil law of negligence. The primary stakeholder in workers compensation is the injured worker seeking timely access to care and the employer/insurer tasked with providing this access. Unfortunately, there often exists a severe power imbalance between the injured worker and the insurance company that is responsible for allowing timely access to appropriate treatment.

The goal of the injured worker is to gain timely access to appropriate care. When a worker is injured, a report is generated and a submission is made to the employer's insurance carrier. If the injury is acute and severe, they will often present to the emergency room for evaluation and treatment. In this situation, the injured worker is protected by the Emergency Medical Treatment and Labor Act (EMTALA) that requires anyone presenting to an emergency department to be stabilized and treated, regardless of their insurance status or ability to pay. For injuries that do not require immediate emergency evaluation, injured workers will often be sent by the employer to the company clinic, but injured workers have the right to seek their own medical treatment. This physician may be their family physician or a specialist such as an orthopedic surgeon or neurologist.

The typical administrative process for a workers' compensation injury is to submit the injury report to the insurance carrier and the injured worker is issued a claim number. The claim number acknowledges that a case file has been created for the particular injured worker. It does not guarantee payment or grant automatic access to appropriate care. The relationship between the legitimately injured/ sickened worker and the insurance carrier paying the medical bills and other compensation is by nature somewhat adversarial. The injured worker wants quality medical treatment to enable a full recovery, and the insurance carrier wants as inexpensive resolution as possible.

We have previously analyzed a cohort group of manual laborers that demonstrated findings consistent with compressive neuropathies of the median and/or ulnar nerves resulting in carpal and/or cubital tunnel syndromes (CTS and CuTS). A comparison group was obtained via a random sample of workers that lacked access to a physician at the time of declaring that they were unable to perform their job function due to upper extremity pain. Workers that lacked access to a physician at the time of declaring that they were unable to perform their job function due to upper extremity pain reached MMI (case closed) on average in 47 months and would have collected over $\$ 250,000$ as the state of Illinois pays $66 \%$ of the employee's salary during the TTD period resulting in $\$ 64,636 /$ year for a worker with a $\$ 100,000 /$ year salary. In contrast, workers that were provided with early access to a physician achieved MMI on average within 5.7months, would collect 
around $\$ 30,700$ on average and be able to return to work in some capacity. Allowing timely access to appropriate care shortened return to work by 3 years and 5 months and demonstrated a net savings of $>$ $\$ 200,000$ for the insurer.

The purpose of this study is to analyze the ability of the injured worker to access to care from primary care physicians, orthopedic surgeons and neurologists in both a dense (Cook County, IL) and sparse (Peoria County, IL) population center.

\section{Materials and methods}

We performed a randomized, consecutive case-series where hypothetical patients called medical offices to attempt to arrange a physician consultation $(\mathrm{N}=300)$. We analyzed the ability of a patient to gain access (an appointment) to a primary care $(\mathrm{N}=100)$, orthopedic $(\mathrm{N}=100)$ and neurology $(\mathrm{N}=100)$ physician after stating that they were injured at work. We analyzed two cohorts, one as an injured worker that was given a claim number $(\mathrm{N}=150)$ and the other that was injured at work but not yet given a claim number $(\mathrm{N}=150)$. We also randomly identified physicians in a densely populated geographic center; Cook County, IL (Population density 5,526per square mile in 2018) and a less densely populated region; Peoria County, IL (Population density 301 per square mile in 2018). ${ }^{3}$ Results were recorded relative to the ability to obtain an appointment or not. Twenty five calls were placed to each subset. The data was then analyzed for the ability to access care through an appointment with the physician office.

To provide a comparison of reimbursement rates, we reviewed fee schedule amounts for the common CPT 99124 (Level 4 evaluation and management (EM)). We reviewed the 2020 reimbursement amount from Medicare and Illinois Workers compensation. We also reviewed the contractual reimbursement amount for our office for Blue Cross Blue Shield, Aetna and United Health Care.

\section{Results}

These results demonstrate that access to care is not universal in the workers compensation population. Even with a claim number (accepted workers compensation injury), 52\% of orthopedic surgeons in Cook County, IL denied an appointment to the injured worker. If the patient did not have a claim number, the denial rate increased to $84 \%$. Injured workers in the less populated areas tended to have greater difficulty gaining access to care with the exception of access to orthopedic care. Denial rates for all physician types exceeded 50\% for injured workers that did not have a claim number (36\% to $100 \%$ denial rate). Having a claim number improved access to care but did not universally allow access to care (16\% to $76 \%$ denial rate) (Table $1 \& 2)$.

Table I Demonstration of universal workers compensation population

\begin{tabular}{llllllll}
\hline Doctor type & Claim type & $\begin{array}{l}\text { Geographic } \\
\text { location }\end{array}$ & Total & $\begin{array}{l}\text { Given } \\
\text { appointment }\end{array}$ & $\begin{array}{l}\text { Denied } \\
\text { appointment }\end{array}$ & $\begin{array}{l}\text { \% Given } \\
\text { access }\end{array}$ & $\begin{array}{l}\text { \% Denied } \\
\text { access }\end{array}$ \\
\hline Orthopedic & No claim \# & Large city & 25 & 4 & 21 & 0.16 & 0.84 \\
Orthopedic & Yes claim \# & Large city & 25 & 12 & 13 & 0.48 & 0.52 \\
Orthopedic & No claim \# & Small City & 25 & 8 & 17 & 0.32 & 0.68 \\
Orthopedic & Yes claim \# & Small City & 25 & 21 & 4 & 0.84 & 0.16 \\
Neurology & No claim \# & Large City & 25 & 4 & 21 & 0.16 & 0.84 \\
Neurology & Yes claim \# & Large City & 25 & 14 & 11 & 0.56 & 0.44 \\
Neurology & No claim \# & Small City & 25 & 1 & 24 & 0.04 & 0.96 \\
Neurology & Yes claim \# & Small City & 25 & 13 & 12 & 0.52 & 0.48 \\
Primary Care & No claim \# & Large City & 25 & 16 & 9 & 0.64 & 0.36 \\
Primary Care & Yes claim \# & Large City & 25 & 20 & 5 & 0.8 & 0.2 \\
Primary Care & No claim \# & Small City & 25 & 0 & 25 & 0 & 1 \\
Primary Care & Yes claim \# & Small City & 25 & 6 & 19 & 0.24 & 0.76
\end{tabular}

Table 2 Reimbursement rates

\begin{tabular}{llllll}
\hline Payer & Workers comp & Medicare & Blue cross & Aetna & United health \\
\hline CPT 99214 & $\$ 113.04-\$ 127.17$ & $\$ 116.53$ & $\$ 98.46$ & $\$ 103.47$ & $\$ 147.69$ \\
\hline
\end{tabular}

*Data is from payer reimbursement rates from 2020. The Illinois Workers Compensation Fee Schedule is based upon four geozips (IL 0I - IL 04)

\section{Discussion}

This study demonstrates how difficult it is to gain access to care as an injured worker. An injured worker in a low densely populated area without a claim number was unable to gain access to a primary care doctor in our cohort (100\% denial rate). Even a patient with an accepted claim number in densely populated Cook County, IL had a $52 \%$ chance of being denied access to care with an orthopedic surgeon (Table $3 \& 4$ ). 
Table $3 \%$ denied access to care with workers compensation injury with a claim number

\begin{tabular}{ll}
\hline Orthopedic large city & $52 \%$ \\
Orthopedic small city & $16 \%$ \\
Neurologist large city & $44 \%$ \\
Neurologist small city & $48 \%$ \\
Primary care large city & $20 \%$ \\
Primary care small city & $76 \%$ \\
\hline
\end{tabular}

Table $4 \%$ denied access to care with workers compensation injury without a claim number

\begin{tabular}{ll}
\hline Orthopedic large city & $84 \%$ \\
Orthopedic small city & $68 \%$ \\
Neurologist large city & $84 \%$ \\
Neurologist small city & $96 \%$ \\
Primary care large city & $36 \%$ \\
Primary care small city & $100 \%$ \\
\hline
\end{tabular}

Ultimately, we need to recognize that the purpose of workers' compensation was to provide timely access to appropriate medical treatment. The compact that the injured worker struck in the 1900's with business leaders was to give up their right to sue in exchange for the basic tenant of no fault and timely access to medical treatment. When Illinois enacted a fee schedule in 2006 and further reduced reimbursement by a $30 \%$ reduction in 2011 , they placed a stress on medical providers that are under significantly different cost structure than other categories of insured patients. They are subjected to utilization review, case managers, independent medical exams, and endless forms that disrupt clinic flow.

We believe the burden placed upon medical providers has affected the ability of the injured worker to gain access to timely and appropriate medical care. Physician offices have to weigh the desire to provide access to all in need while dealing with the reality that a medical office is a business. If the cost to provide care exceeds the reimbursement, the physician's office will cease to exist and no one will receive care. Our data demonstrates that the reimbursement rate for the common
CPT code 99214 is similar for Medicare patients and injured workers. If the physician feels that the added cost and bureaucratic burden exceeds the payment amount received for treatment of the injured worker, the physician may choose not to provide access to this subset of patients. We have previously demonstrated that $32 \%$ of workers' compensation claims in our practice are never paid while the average time in collections was 3.6 years (1,342 days). ${ }^{4}$ These realities result in a cost/benefit analysis that leads many providers to close their offices to the treatment of the injured worker. This lack of appropriate access has a subsequent effect of making many who are legitimately injured while at work due to no fault of their own, financially destitute.

\section{Sources of support}

None.

\section{Author's contributions}

BAR wrote the manuscript and performed statistical analysis; SMR conducted the data collection and created the data spreadsheet. All authors reviewed the final manuscript.

\section{Acknowledgments}

None.

\section{Conflicts of interest}

The authors declare there are no conflicts of interest.

\section{Funding}

None.

\section{References}

1. (820 ILCS 305/) Workers' Compensation Act.

2. Blair AR, William SR, Brent R. Removal of barriers to care result in improved outcomes for manual laborers with compressive neuropathies. MOJ Orthop Rheumatol. 2015;2(2):62-65.

3. https://statisticalatlas.com/county/Illinois/Peoria-County/ Population\#figure/county-in-peoria-area

4. Rhode BA. The three D's of insurance: delay, deny and do not pay analysis of collection rates for Illinois workers' compensation patients. MOJ Orthop Rheumatol. 2015;3(1):267-269. 